\title{
EFFECT OF CASEIN PHOSPO-PEPTIDE-AMORPHOUS CALCIUM PHOSPHATE ON SOME SALIVARY IONS CONCENTRATION IN CHILDREN WITH EARLY CHILDHOOD CARIES
}

\author{
Ragab Abd Elmohsen Attia Abd Elftah ${ }^{1 *}$, Alaa Al Deen Abdalla Mohamed Ismail², Alaa Nabil Abbas ${ }^{3}$
}

\begin{abstract}
Objective: This study was directed to evaluate effect of Casein Phospho Peptide-Amorphous Calcium Phosphate on Some Salivary Ions Concentration (Calcium, Phosphate, Fluoride) in Children with Early Childhood Caries in comparison with the use CPP-ACPF and sodium fluoride 5\% varnish.Subjects and methods: A total of 36 children with early child-caries (ECC), aged between 2.5-5 years were selected for this clinical trial study. Registered children were split into three groups at random according to the tested materials, group A; treated with non-fluoridated CPP-ACP-paste, group B; treated with CPP-ACPF-paste, and group $\mathrm{C}$; treated with $5 \%$ sodium fluoride $(\mathrm{NaF})$ paste. At first, $1 \mathrm{ml}$ of unstimulated saliva was collected from whole enrolled children. In the next step, each tested material was applied on the tooth surfaces and then the saliva sampling was performed after 48 hours. The amount of phosphate ions was measured by spectrophotometer, while, calcium, and fluoride ions were measured by chromatographic instrument. Results: This study revealed that; significant increase in phosphate and calcium ions concentration of the saliva before and after applying the CPP-ACP and CPP-ACPF pastes. However, the applying of CPP-ACPF paste, and 5\% sodium fluoride paste significantly raise the fluoride scores of the saliva.Conclusion: In this study, the utilize of CPP-ACP also the use of CPP-ACPF pastes can ease the remineralization of tooth surfaces and is beneficial for protecting the primary teeth.
\end{abstract}

KEYWORDS: CPP-ACP, CPP-ACPF, Calcium, Fluoride, Phosphate, Saliva.

\section{INTRODUCTION}

Dental caries is considered as an infectious disease defined as localized destruction of mineralized tooth structures by microorganism ${ }^{(1)}$. Children's oral cavity is a rather ideal environment for the growth of bacteria because it has a proper temperature, contains the necessary nutrients, has sufficient moisture and proper surfaces for bacterial adhesion ${ }^{(2)}$.
Dental caries can affect the children's quality of life. In most small children (less than 2 years old), dental decay led to reduced weight gain and reduced growth ${ }^{(3)}$. Impaired speech development and reduced self-esteem have been reported to be associated with early tooth lack caused by dental caries ${ }^{(4)}$.

Sufficient amounts of calcium, phosphate, also the amount of fluoride ions must be obtainable in saliva for net remineralization to take place, but

1. Masters Candidate, Dentist at the Ministry of Health, Department of Pedodontics and Oral Health, Faculty of Dental Medicine, Boys, Cairo, Al-Azhar University

2. Associate Professor, Department of Pedodontics and Oral Health, Faculty of Dental Medicine, Boys, Cairo, Al-Azhar University.

3. Lecturer, Department of Pedodontics and Oral Health, Faculty of Dental Medicine, Boys, Cairo, Al Azhar University.

-Corresponding author: rasad.ragab@yahoo.com 
this procedure is normally bound by the amount of available calcium and phosphate ${ }^{(5)}$. Therefore, the focus on the use of non-invasive treatment approaches such as use of non-fluoridated and fluoridated Casein Phospho Peptide-Amorphous Calcium Phosphate, and fluoridated paste has increase lately to enhance the remineralization and prevent dental caries ${ }^{(6)}$.

CPP-ACP is beneficial in the treating of dental caries, white spot lesions, hypocalcified enamel, dentin hypersensitivity, mild fluorosis, and erosion $^{(7)}$. CPP-ACP can also block demineralization concerning the brackets and other orthodontic appliances and ease a normal post-eruptive maturation procedure $^{(8)}$.

CPP-ACP is a bioactive substance with a base of milk products, consisting of two accessories: casein phosphor-peptides (CPP) and amorphous calcium phosphate (ACP) ${ }^{(9)}$. CPP has a major potential to stabilize calcium and phosphate in "nanocluster" forms of ions in resolution and to uncommonly promote the score of calcium and phosphate in dental plaque ${ }^{(7)}$. CPP can link to the biofilm, enamel and soft tissues, thereby delivering the calcium and phosphate ions exactly to the sites where they are necessary ${ }^{(8,10)}$. The free calcium and phosphate ions move out of the CPP, enter the enamel prisms, and get the apatite crystals ${ }^{(10)}$.

The fluoridated CPP-ACP "CPP-ACPF" contains CPP-ACP plus sodium fluoride 0.2\% (900 $\mathrm{ppm})$ that is very similar to the quantity of fluoride in the toothpaste manufactured for adults ${ }^{(11)}$. The active ingredient of fluoridated paste is usually 5\% sodium fluoride, $(22,600 \mathrm{ppm} \text { fluoride })^{(12)}$. Sodium fluoride paste is utilized to block caries development, hold early enamel and even soft dentine caries by promotion of remineralization of carious tooth substance by formation of calcium/fluoridelike material on the tooth surface. It is also utilized to treat tooth hypersensitivity ${ }^{(13)}$.
Therefore, the purpose of this study was to adjust the focus of calcium, phosphate also the concentration of fluoride ions in the saliva of children aged among 2.5-5 years before and after applying non-fluoridated and fluoridated CPP-ACP pastes and also 5\% sodium fluoride paste. The supposition was that the utilization of CPP-ACPF paste has a considerable influence on the concentration of calcium, phosphate and fluoride ions in the saliva.

\section{SUBJECTS AND METHODS}

This study was conducted on 36 patients with ECC aged between 2.5-5 years, with no systemic disease. Children were selected from that attending outpatient of pedodontics clinic of Al-Azhar University, Cairo (boys).

All children were divided randomly into three equal groups $(n=12)$ according to the material used as the follow:

- Group A: children treated with application of CPP-ACP paste.

- Group B: children treated with application of CPP-ACPF paste.

- Group C: children treated with application of $5 \%$ sodium fluoride paste.

\section{- Patient Selection:}

Selection of patients were based on specific inclusion and also exclusion criteria as the follow:

\section{A. Inclusion Criteria:}

Cooperative patients and their parents; and patients with early childhood caries.

\section{B. Exclusion Criteria:}

Patients with systemic disease, without caries and good oral hygiene.

\section{- Ethical Consideration:}

This study was carried out after approval of ethical committee, Faculty of Dental Medicine, Al-Azhar University, Cairo, Boys (EC Ref No. 324/346/10/09/19). 


\section{- Patient Consent:}

Each parent/care-giver signed an informed consent having details about the whole treatment procedure before starting of the study.

\section{- Procedure:}

After taking the informed agreement, the bacterial plaque was extracted utilizing a slow-speed hand part and a soft rubber cup without utilizing any other substances. Children/parents were asked to avert brushing teeth, utilizing dental floss or fluoride and other medical substances for 48 hours, and then sampling of saliva was performed ${ }^{(8)}$.

\section{Collecting and preparing saliva samples:}

Unstimulated salivary samples were collected in sterile container in the morning (between 8 am and $10 \mathrm{am}$ ) from each enrolled child. Collection of salivary samples was collected from patients by asking each child to spit in a sterile container. All the samples that were collected after application of the different tested three materials were stored in ice container and immediately transferred to the laboratory (Central Laboratory Faculty of Agriculture, Mansoura University) for saliva preparation and measuring the different ion concentrations. Samples following the same procedure, 36 saliva samples were collected and labeled after application of ACP-CPP, ACP-CPPF, and 5\% sodium fluoride for 48 hours ${ }^{(8,9)}$. For the preparation of the samples, $3 \mathrm{ml}$ of the saliva sample was mixed with $8 \mathrm{ml}$ of $69 \%$ nitric acid and $2 \mathrm{ml}$ of hydrogen peroxide was added to the mixture; then, to water added to complete the beaker scale to $100 \mathrm{ml}{ }^{(8,9)}$. After that the mixture were putted in advanced microwave digestion system (ETHOS Easy, Milestone Co., USA) for 45 mints to evenly and homogenously distributes the mixture (Figure 1).

\section{- Ion measuring:}

The amount of phosphate ions of saliva samples was measured by spectrophotometer (Figure 2), and the amount of calcium and fluoride ions was measured by ion chromatography instrument (Figure 3) using their specific columns ${ }^{(8)}$.

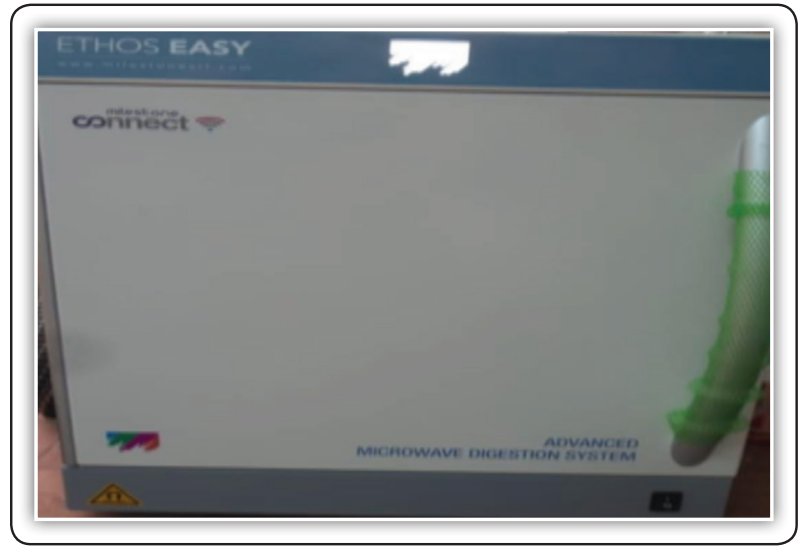

FIG (1) ETHOS Easy; advanced microwave digestion system.

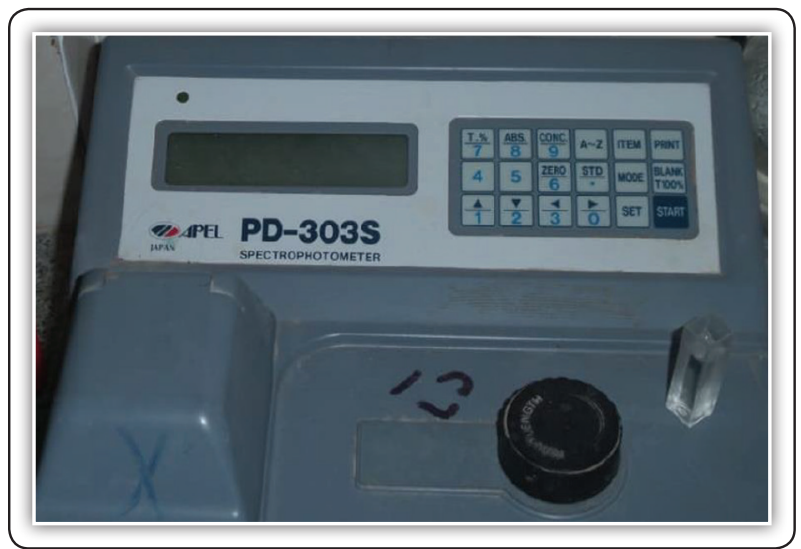

FIG (2) Spectrophotometer.

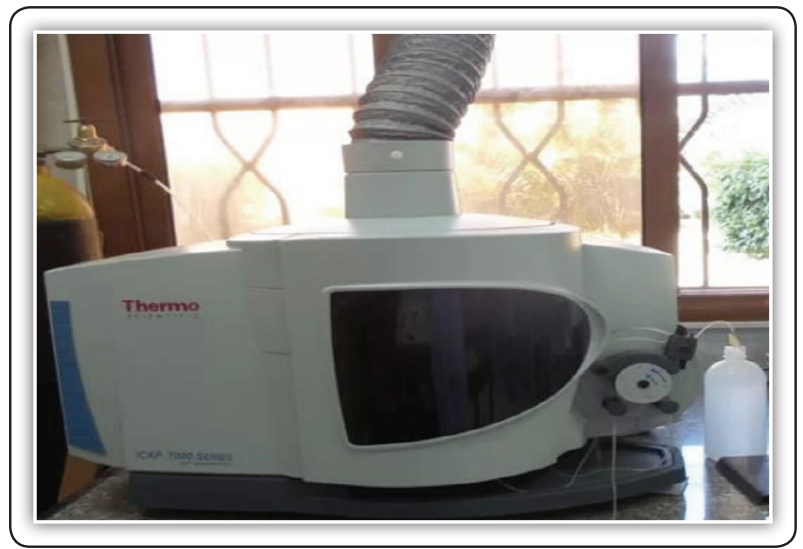

FIG (3) Ion chromatography instrument.

\section{Statistical analysis:}

All results were collected, tabulated, and statistically analyzed utilizing paired $t$-test to compare the same group before and after the enforcement of the material, and One-way ANOVA test to compare the 
three different groups postoperatively at a $p<0.05$ score of significance.

\section{RESULTS}

\section{Phosphate ion levels:}

The results of paired $t$-test showed that there was significant increase of phosphate ion concentration of the samples of saliva after application of
CPP-ACP, and CPP-ACPF for 48 hours. However, there was non-significant increase of phosphate ion concentration of the samples of saliva after application of 5\% sodium fluoride for 48 hours (Table 1). While, the results of One-way ANOVA and post Tukey's test results showed no-statistically significant difference between phosphate ion concentration of saliva samples CPP-ACP, and CPP-ACPF after application for 48 hours (Table 2).

Table (1): Phosphate ion levels at baseline and after 48 hours of application of ACP-CPP, ACP-CPPF, and $5 \%$ sodium fluoride paste using paired $t$-test:

\begin{tabular}{|c|c|c|c|c|c|c|}
\hline \multirow{2}{*}{ Variable } & Group & $\begin{array}{c}\text { Base-line } \\
\text { Mean } \pm \text { SD }(\boldsymbol{\mu g} / \mathbf{m l})\end{array}$ & $\begin{array}{c}\text { After } \mathbf{4 8} \text { hours } \\
\text { Mean } \pm \text { SD }(\boldsymbol{\mu g} / \mathbf{m l})\end{array}$ & P-value & t-value & df \\
\hline \multirow{2}{*}{$\begin{array}{c}\text { Phosphate ion } \\
\text { levels }\end{array}$} & Group A & $0.493 \pm 0.07$ & $0.688 \pm 0.16$ & $<0.00001 *$ & 6.5414 & 11 \\
\cline { 2 - 8 } & Group B & $0.412 \pm 0.07$ & $0.635 \pm 0.11$ & $<0.00001 *$ & 14.1967 & 11 \\
\cline { 2 - 8 } & Group C & $0.502 \pm 0.08$ & $0.506 \pm 0.08$ & 0.3177 & 1.0467 & 11 \\
\hline
\end{tabular}

*; The result is significant at $p<0.05$.

Table (2): Comparison of phosphate ion levels after different treatments among the tested groups using One-way ANOVA test:

\begin{tabular}{|l|c|c|c|c|}
\hline Variable & Mean $(\boldsymbol{\mu g} / \mathbf{m l})$ & SD & f-ratio & P-value \\
\cline { 1 - 2 } Group A & $0.688^{\mathrm{A}}$ & 0.16 & & \\
\cline { 1 - 2 } Group B & $0.635^{\mathrm{A}}$ & 0.11 & \multirow{2}{*}{7.13282} & $0.002664^{*}$ \\
\cline { 1 - 2 } Group C & $0.506^{\mathrm{B}}$ & 0.08 & & \\
\hline
\end{tabular}

*; The result is significant at $p<0.05$.

$n s$; non-significant $(p>0.05)$

Different letter in the selfsame column indicating statistically significant difference $(p<0.05)$.

\section{Calcium ion levels:}

The results of paired $t$-test showed that there was significant increase of calcium ion concentration of the samples of saliva after application of CPP-ACP, and CPP-ACPF for 48 hours. However, there was a non-significant increase of calcium ion concentra- tion of the samples of saliva after application of 5\% sodium fluoride for 48 hours (Table 3). While, the results of One-way ANOVA and post Tukey's test results showed no-statistically significant difference between calcium ion concentration of saliva samples CPP-ACP, and CPP-ACPF after application for 48 hours (Table 4 ).

\section{Fluoride ion levels:}

The results of paired $t$-test showed that there was significant increase of fluoride ion concentration of the samples of saliva after application of $\mathrm{CPP}-\mathrm{ACPF}$, and $5 \%$ sodium fluoride for 48 hours. However, there was non-significant increase of fluoride ion concentration of the samples of saliva after application of CPP-ACP for 48 hours (Table 5). While, the results of One-way ANVA and pst Tukey's test results showed no-statistically significant difference between fluoride ion concentration of saliva samples CPP-ACPF, and 5\% sodium fluoride after application for 48 hours (Table 6). 
Table (3): Calcium ion levels at baseline and after 48 hours of application of ACP-CPP, ACP-CPPF, and $5 \%$ sodium fluoride paste using paired $t$-test:

\begin{tabular}{|c|c|c|c|c|c|c|}
\hline Variable & Group & $\begin{array}{c}\text { Base-line } \\
\text { Mean } \pm \text { SD }(\boldsymbol{\mu g} / \mathbf{m l})\end{array}$ & $\begin{array}{c}\text { After 48 hours } \\
\text { Mean } \pm \text { SD }(\boldsymbol{\mu g} / \mathbf{m l})\end{array}$ & P-value & t-value & df \\
\hline \multirow{2}{*}{$\begin{array}{c}\text { Calcium ion } \\
\text { levels }\end{array}$} & Group A & $12.78 \pm 1.77$ & $35.85 \pm 5.17$ & $<0.00001^{*}$ & 23.3949 & 11 \\
\cline { 2 - 7 } & Group B & $12.92 \pm 2.09$ & $38.68 \pm 5.65$ & $<0.00001^{*}$ & 24.3622 & 11 \\
\cline { 2 - 7 } & Group C & $13.09 \pm 1.92$ & $13.10 \pm 1.95$ & 0.8742 & 0.1620 & 11 \\
\hline
\end{tabular}

*; The result is significant at $p<0.05$.

Table (4): Comparison of calcium ion levels after different treatments among the tested groups using Oneway ANOVA test:

\begin{tabular}{|c|c|c|c|c|}
\hline Variable & Mean $(\boldsymbol{\mu g} / \mathbf{m l})$ & SD & f-ratio & P-value \\
\hline Group A & $35.85^{\mathrm{A}}$ & 5.17 & \multirow{2}{*}{113.67398} & $<0.00001^{*}$ \\
\hline Group B & $38.68^{\mathrm{A}}$ & 5.65 & & \\
\hline Group C & $13.09^{\mathrm{B}}$ & 1.92 & & \\
\hline
\end{tabular}

*; The result is significant at $p<0.05$.

$n s$; non-significant $(p>0.05)$

Different letter in the selfsame column indicating statistically significant difference $(p<0.05)$.

Table (5): fluoride ion levels at baseline and after 48 hours of application of ACP-CPP, ACP-CPPF, and $5 \%$ sodium fluoride paste using paired $t$-test:

\begin{tabular}{|c|c|c|c|c|c|c|}
\hline \multirow{2}{*}{ Variable } & Group & $\begin{array}{c}\text { Base-line } \\
\text { Mean } \pm \text { SD }(\boldsymbol{\mu g} / \mathbf{m l})\end{array}$ & $\begin{array}{c}\text { After } 48 \text { hours } \\
\text { Mean } \pm \text { SD }(\boldsymbol{\mu g} / \mathbf{m l})\end{array}$ & P-value & t-value & df \\
\hline \multirow{3}{*}{$\begin{array}{c}\text { Fluoride ion } \\
\text { levels }\end{array}$} & Group A & $0.145 \pm 0.014$ & $0.140 .013 \pm 7$ & 0.6725 & 0.4342 & 11 \\
\cline { 2 - 8 } & Group B & $0.156 \pm 0.012$ & $0.550 .108 \pm 4$ & $<0.00001 *$ & 13.9718 & 11 \\
\cline { 2 - 8 } & Group C & $0.144 \pm 0.019$ & $0.583 \pm 0.145$ & $<0.00001 *$ & 11.0234 & 11 \\
\hline
\end{tabular}

*; The result is significant at $p<0.05$.

Table (6): Comparison of fluoride ion levels after different treatments among the tested groups using Oneway ANOVA test:

\begin{tabular}{|c|c|c|c|c|}
\hline Variable & Mean $(\mu \mathrm{g} / \mathrm{ml})$ & SD & $f$-ratio & $P$-value \\
\hline Group A & $0.147^{\mathrm{B}}$ & 0.013 & \multirow{2}{*}{65.11767} & $<0.00001^{*}$ \\
\hline Group B & $0.554^{\mathrm{A}}$ & 0.108 & & \\
\hline Group C & $0.583^{\mathrm{A}}$ & 0.145 & & \\
\hline
\end{tabular}

*; The result is significant at $p<0.05$.

$n s$; non-significant $(p>0.05)$

Different letter in the selfsame column indicating statistically significant difference $(p<0.05)$. 


\section{DISCUSSION}

Saliva can significantly influence the caries process as well as it is necessary to maintain the integrity of the tooth structure ${ }^{(5)}$. Furthermore, there was proved relationship between the content of the saliva, also the dental caries ${ }^{(8,9)}$. Therefore, saliva could prevent the incidence of the dental caries through keeping the balance among demineralization and remineralization of teeth ${ }^{(14)}$.

However, Juárez-López et al ${ }^{(15)}$ revealed that the saliva alone cannot stimulate suitable conditions for remineralization; thus, the utilization of mineralizing agents is vital to make an environment favorable for remineralization. Therefore, the process of demineralization/remineralization balance depends not only on the saliva content of calcium and phosphorus but also, on their concentrations ${ }^{(16)}$. It was observed that salivary calcium concentration decreased with the increasing carious activity ${ }^{(9)}$.

The results of this study found that the utilization of CPP-ACP, and CPP-ACPF pastes significantly increased the saliva phosphate and calcium levels. This may be because of CCP containing the cluster sequence $\operatorname{Ser}(\mathrm{p})-\operatorname{Ser}(\mathrm{p})-\operatorname{Ser}(\mathrm{p})-\mathrm{Glu}-\mathrm{Glu}$ - have a remarkable ability to stabilize ACP in the metastable solution. By the multiple phosphoryl remains, the CPP links to form nanoclusters of ACP, barring their growth to the critical size required for nucleation and phase processing ${ }^{(17)}$. CPP can set over 100 times more calcium phosphate than is normally conceivable in an aqueous resolution ${ }^{(9,18)}$.

This is agreement with the results of the previous study of Poureslami et al, ${ }^{(8)}$, who concluded that utilizing CPP-ACP can significantly increase the concentration on both phosphate and calcium ions in saliva after application for 10 minutes. However, Kakatkar et al, ${ }^{(19)}$ reported that the use of chewing gum that contains CPP-ACP significantly increase the salivary calcium ion concentration; however, it significantly decreases the phosphate ion concentration for up to 1 hour after chewing the gum, as compared to the baseline. This pseudo decreases in phosphate concentration could be attributed to the increase in the salivary flow average after chewing the CPP-ACP containing gum ${ }^{(9,19)}$.

Additionally, the results of the current study revealed that the use of $5 \%$ sodium fluoride cannot increase the concentration of phosphate and calcium ions significantly of saliva. This may be because of the utilized fluoride paste in this study did not containing CPP-ACP that is available in other products such as MI Paste; which contain 2\% CPPACP in addition to $5 \%$ sodium fluoride ${ }^{(20,21)}$. This agreed with the results of Hay and Thomson, (22) which reported that the utilization of CPP-ACP significantly decrease caries when compared with 0.05 $\mathrm{NaF}$ mouth washing between individuals with dry mouth.

Fluoride ions play several significant roles in caries-prevention; these include the formation of fluorapatite crystals, which are more acid resistant than hydroxyapatite, interference with ionic bonding during plaque and pellicle formation, the enhancement of remineralization and the inhibition of the microbial growth and metabolism ${ }^{(8,23)}$.

The results of salivary fluoride ion concentration in the present study significantly increase after the use of CPP-ACPF past and 5\% sodium fluoride for 48 hours. This significant raise in the fluoride concentration is related to the availability of high amounts of calcium ions on plaque in children with ECC ${ }^{(8)}$. This may be due to the fact that fluoride accumulate on the plaque in the presence of calcium ions ${ }^{(24)}$.

While, the insignificant increase in fluoride in the group of children that was treated with CPP$\mathrm{ACP}$, may be due to the absence of fluoride in their composition. This agreed with the results of Srinivasan et al, ${ }^{(15)}$ and El-Zayate, ${ }^{(25)}$ who showed that the utilize of CPP-ACP with $900 \mathrm{ppm}$ fluoride significantly remineralized softened enamel, with greater remineralization potential of CPP-ACPF than CPP-ACP due to presence of fluoride. 


\section{CONCLUSION}

In this study, the utilization of CPP-ACP and CPP-ACPF pastes significantly increased levels of the calcium and phosphate ions of saliva. While, the use of CPP-ACPF paste and 5\% sodium significantly raised the levels of fluoride ions of the saliva. Hence, the utilize of CPP-ACPF paste can ease the remineralization of tooth surfaces and is beneficial to protect the primary teeth, especially when oral hygiene is not desirable as in children with ECC.

\section{REFERENCES}

1. Featherstone J. The continuum of dental caries-evidence for a dynamic disease process. J Dent Res. 2004; 83:39-42.

2. Shahrabi M, Nikfarjam J, Alikhani A, Akhoundi N, Ashtiani M, Seraj B. A comparison of salivary calcium, phosphate, and alkaline phosphatase in children with severe, moderate caries, and caries free in Tehran's kindergartens. J Indian Soc Pedod Prev Dent. 2008; 26:74-7.

3. Petersen PE, Estupinan-Day S, Ndiaye C. WHO's action for continuous improvement in oral health. Bull World Health Organ. 2005; 83:642-47.

4. Çolak H, Dülgergil ÇT, Dalli M, et al. Early childhood caries update: A review of causes, diagnoses, and treatments. J Nat Sci Biol Med. 2013; 4:29-38.

5. Hegde MN, Devadiga D, Jemsily PA. Comparative evaluation of effect of acidic beverage on enamel surface pretreated with various remineralizing agents: An In vitro study. J Conserv Dent. 2012; 15:351-56.

6. Rezvani M, Karimi M, Akhavan Rasoolzade R.Comparing the Effects of Whey Extract and Casein PhosphopeptideAmorphous Calcium Phosphate (CPP-ACP) on Enamel Microhardness. J Dent (Shiraz). 2015; 16:49-53.

7. Reema SD, Lahiri PK, Roy SS. Review of casein phosphopeptides-amorphous calcium phosphate. Chin J Dent Res. 2014; 17:7-14.

8. Poureslami HR, Hoseinifar Ra, Hoseinifar Re, Sharifi H, Poureslami P. Concentration of Calcium, Phosphate and Fluoride Ions in Microbial Plaque and Saliva after Using CPP-ACP Paste in 6-9-year-old Children. J Dent Biomater, 2016;3: 214-219.

9. Santhosh BP, Jethmalani P, Shashibhushan KK, Subba Reddy VV. Effect of casein phosphopeptide - amorphous calcium phosphate containing chewing gum on salivary concentration of calcium and phosphorus: An in-vivo study. J Indian Soc Pedod Prev Dent. 2012; 30:146-50.

10. Jayarajan J, Janardhanam P, Jayakumar P, et al. Efficacy of CPP-ACP and CPP-ACPF on enamel remineralizationAn in vitro study using scanning electron microscope and DIAGNOdent ${ }^{\circledR}$. Indian J Dent Res. 2011; 22:77-82.

11. Somani R, Jaidka S, Singh DJ. Remineralizing potential of various agents on dental erosion. J Oral Biol Craniofac Res. 2014; 4:104-08.

12. Strohmenger L, Brambilla E. The use of fluoride pastes in the prevention Of dental caries: a short review. Oral Dis. 2001; 7:71-80.

13. Chu C, Lo ECM. A review of sodium fluoride paste. Gen Dent. 2006; 54:247- 53.

14. Juárez-López ML, Hernández-Palacios RD, HernándezGuerrero JC, Jiménez-Farfán D, Molina-Frechero N. Preventive and remineralization effect over incipient lesions of caries decay by phosphopeptide-amorphous calcium phosphate. Rev Invest Clin. 2014 66:144-51.

15. Srinivasan N, Kavitha M, Loganathan SC. Comparison of the remineralization potential of $\mathrm{CPP}-\mathrm{ACP}$ and $\mathrm{CPP}-\mathrm{ACP}$ with 900ppm fluoride on eroded human enamel: An in-situ study. Arch Oral Biol. 2010; 55:541-44.

16. Sitthisettapong $\mathrm{T}$, Phantumvanit $\mathrm{P}$, Huebner $\mathrm{C}$, Derouen $\mathrm{T}$. Effect of CPP-ACP paste on dental caries in primary teeth: a randomized trial. J Dent Res. 2012; 91:847-52.

17. Shen P, Cai F, Nowicki A, Vincent J, Reynolds EC. Remineralization of enamel subsurface lesions by sugar-free chewing gum containing casein phosphopeptide-amorphous calcium phosphate. J Dent Rest. 2001; 80:2066-70.

18. Imani MM, Safaei M, Afnaniesfandabad A, Moradpoor H, Sadeghi M, Golshah A, et al. Efficacy of CPP-ACP and CPP-ACPF for Prevention and Remineralization of White Spot Lesions in Orthodontic Patients: A systematic review of randomized controlled clinical trials. Acta Informatica Medica. 2019; 27:199-204.

19. Kakatkar G, Nagarajappa R, Bhat N. Evaluation of Salivary Calcium and Phosphorous Concentration Before and After Chewing CPP-ACP Containing Chewing Gum. Acta stomatologica Croatica. 2012; 46:117-25.

20. Salman NR, El-Tekeya MM, Bakry N, Soliman S. Remineralization effect of fluoride paste containing casein phosphopeptide amorphous calcium phosphate on caries-like lesions in primary teeth (in vitro study). Alex Dent J. 2019; 44:13-16. 
21. Varma V, Hegde KS, Bhat SS, Sargod SS, Rao HA. Comparative Evaluation of Remineralization Potential of Two Pastes Containing CPP-ACP and Tricalcium Phosphate: An In Vitro Study. Int J Clin Pediatr Dent. 2019; 12:233-36.

22. Hay KD, Thomson WM. A clinical trial of the anticaries efficacy of casein derivatives complexed with calcium phosphate in patients with salivary gland dysfunction. Oral Surg Oral Med Oral Pathol Oral Radiol Endod. 2002; 93:271-75.

23. Salama RI, Taju WG. Comparing the effect of three different fluoride pastes on salivary fluoride ions and strepto- coccus mutants' levels: clinical trial. Int J Health Sci Res. 2019; 9:280-85

24. Kato K, Nakagaki H, Arai K, et al. The influence of salivary variables on fluoride retention in dental plaque exposed to a mineral-enriching solution. Caries Res. 2002; 36:58-63.

25. El Zayat A. The effect of casein phosphopeptide- amorphous calcium phosphate on remineralization of carieslike lesions in primary teeth. MS thesis; Faculty of Dentistry, Alexandria University; 2012. 